\title{
INFLUENCE OF INTERMETALLIC PHASE PRECIPITATION DURING PROLONGED SERVICE IN ALLOY 625 ON ITS PROPERTIES
}

\author{
M. Sundararaman, P. Mukhopadhyay and S. Banerjee \\ Materials Science Division \\ Bhabha Atomic Research Centre \\ Mumbai 400085, India
}

\begin{abstract}
The results of a microstructural investigation on Alloy 625 which has undergone prolonged service at temperatures close to but less than $600^{\circ} \mathrm{C}$ are reported in this paper. A uniform distribution of precipitates of an intermetallic phase, $\mathrm{Ni}_{2}(\mathrm{Cr}, \mathrm{Mo})$ with $\mathrm{Pt}_{2} \mathrm{Mo}$ type structure has been observed in addition to that of the $\gamma^{\prime \prime}$ phase for service periods exceeding $28,000 \mathrm{~h}$. The $\mathrm{Ni}_{2}(\mathrm{Cr}, \mathrm{Mo})$ phase has been found to dissolve on ageing at temperatures above $600^{\circ} \mathrm{C}$. The dissolution of this phase has been noticed to result in a reduction in hardness and impact properties of the alloy. The occurrence of $\mathrm{Ni}_{2}(\mathrm{Cr}, \mathrm{Mo})$ phase in this alloy has been discussed by taking the alloy chemistry into consideration.

Apart from these intermetallic phases, precipitation of $\mathrm{M}_{6} \mathrm{C}$ carbide particles within the austenite matrix and the formation of a near continuous film comprising discrete $\mathrm{M}_{6} \mathrm{C} / \mathrm{M}_{23} \mathrm{C}_{6}$ carbide precipitates at grain boundaries have been noticed in the alloy after prolonged service. Energy Dispersive Spectroscopy(EDS) analysis has revealed that the majority of the carbides precipitating at the grain boundaries at temperatures around $600^{\circ} \mathrm{C}$ are of $\mathrm{M}_{23} \mathrm{C}_{6}$ type. The influence of the intermetallic and the carbide phase precipitates on the performance, properties and life of Alloy 625 is also discussed in this paper.
\end{abstract}

Supcrallos ? 78.625 .706 and Various Derivatives

Edited by E.A. i.oria

TMS (the Mincrals. Metals \& Materials Society). $200 \mathrm{i}$ 


\section{Introduction}

Alloy 625 is a nickel base superalloy which has found extensive use in the petrochemical and the aerospace industries and in many marine engineering applications. Although the alloy was originally designed as a solid solution alloy, it has subsequently been shown that the precipitation of intermetallic phases occurs in it during ageing treatments or during service at temperatures in the range of $600^{\circ} \mathrm{C}$ to $750^{\circ} \mathrm{C}[1]$. Unlike the majority of precipitation hardenable nickel base alloys in which strengthening is brought about mainly by precipitates of the metastable $\gamma^{\prime}$ or $\mathrm{Ni}_{3}(\mathrm{Al}$, Ti) phase (ordered cubic $\mathrm{L}_{2}$ structure), in Alloy 625 precipitation hardening is caused primarily by precipitates of the $\gamma^{\prime \prime}$ or $\mathrm{Ni}_{3}(\mathrm{Nb}, \mathrm{Al}, \mathrm{Ti})$ phase which has the ordered, body centred tetragonal $\mathrm{DO}_{22}$ structure [2]. This metastable phase precipitates on ageing at temperatures above $600^{\circ} \mathrm{C}$. The equilibrium intermetallic phase that forms in this alloy is the orthorhombic $\delta$ or $\mathrm{Ni}_{3}(\mathrm{Nb}, \mathrm{Mo})$ phase (DO structure) [2,3-8]. This phase can form directly from the supersaturated solid solution on ageing at relatively high temperatures. Prolonged ageing at relatively low temperatures also causes the precipitates of the metastable $\gamma^{\prime \prime}$ phase to be replaced by those of the equilibrium $\delta$ phase $[6,9]$.

The microstructure that develops in this alloy after ageing or service for very long periods and the effect of such a microstructure on its mechanical properties have been investigated by a few researchers in the recent years. Radavich and Fort [9] have studied the microstructure of Alloy 625 after ageing in the temperature range of $650{ }^{\circ} \mathrm{C}$ to $870^{\circ} \mathrm{C}$ for up to $46000 \mathrm{~h}$ by scanning electron microscopy (SEM) and X-ray diffraction (XRD). Thomas and Tait [10] have examined the microstructure and the mechanical properties of the alloy after it had seen long-term service (about $50000 \mathrm{~h}$ ) at temperatures of around $500^{\circ} \mathrm{C}$ as the material of construction of feed stock superheaters in a petrochemical plant. They have found that on being subjected to this treatment the alloy hardens significantly but its ductility and toughness at room temperature and weldability show a conspicuous deterioration. However, short ageing treatments in the temperature range of $650^{\circ} \mathrm{C}$ $700^{\circ} \mathrm{C}$ result in a considerable reduction in hardness and increase in toughness. Transmission electron microscopy (TEM) of specimens obtained from the post-service material has revealed the presence of extra reflections in $<001>$ zone selected area diffraction (SAD) patterns in addition to the reflections corresponding to the austenite and the $\gamma^{\prime \prime}$ phases. They have attributed these additional reflections to "a commensurate superstructure in the matrix, the origin of which is unknown". Bajaj et al [11], in their study on the precipitation behaviour of Alloy 625 exposed at $360^{\circ} \mathrm{C}$ to a fluence of $2.3 \times 10^{20}$ neutrons $/ \mathrm{cm}^{2}$, have observed the precipitation of a new phase showing SAD patterns similar to that observed by Thomas and Tait[10] and identified its structure to be of the $\mathrm{Pt}_{2} \mathrm{Mo}$ type; they have tentatively assigned the composition $\mathrm{Ni}_{2}(\mathrm{Nb}, \mathrm{Mo})$ to this phase. Sundararaman et al[12] in an earlier study of Alloy 625 exposed to $70000 \mathrm{~h}$ identified the precipitation of a phase with $\mathrm{Pt}_{2} \mathrm{Mo}$ structure and $\mathrm{Ni}_{2}(\mathrm{Cr}, \mathrm{Mo})$ composition.

The present paper reports the results of a microstructural characterisation study carried out on Alloy 625 exposed to service temperatures close to but lower than $600^{\circ} \mathrm{C}$ for different periods of time. The effect of post service ageing treatments on hardness and microstructure of the alloy is also described. In addition, the nature of grain boundary carbide precipitates has been studied and their role on the performance, properties and life of Alloy 625 has been discussed.

Table I. Chemical composition of Alloy 625

\begin{tabular}{|l|c|c|c|c|c|c|c|c|c|c|c|}
\hline & \multicolumn{10}{|c|}{ Element } \\
\hline & $\mathrm{Ni}$ & $\mathrm{Cr}$ & $\mathrm{Mo}$ & $\mathrm{Fe}$ & $\mathrm{Nb}$ & $\mathrm{Al}$ & $\mathrm{Ti}$ & $\mathrm{Co}$ & $\mathrm{Mn}$ & $\mathrm{Si}$ & $\mathrm{C}$ \\
& & & & & & & & & & & \\
\hline $\mathrm{W} \mathrm{t} \%$ & 60.81 & 21.73 & 8.82 & 3.92 & 3.90 & 0.17 & 0.23 & 0.08 & 0.14 & 0.15 & 0.05 \\
\hline
\end{tabular}


Table II. Variation of Hardness as a function of post service heat treatment.

\begin{tabular}{|l|c|}
\hline \multicolumn{1}{|c|}{ Heat treatment } & Vickers Hardness \\
\hline Solution annealed & 200 \\
Service Alloy $\left(70000 \mathrm{~h}, \mathrm{~T}<600^{\circ} \mathrm{C}\right)$ & 359 \\
Service - Aged $650^{\circ} \mathrm{C}-5 \mathrm{~h}$ & 275 \\
Service - Aged $650^{\circ} \mathrm{C}-9 \mathrm{~h}$ & 281 \\
Service - Aged $650^{\circ} \mathrm{C}-24 \mathrm{~h}$ & 273 \\
Service - Aged $700^{\circ} \mathrm{C}-10 \mathrm{~h}$ & 305 \\
Service - Aged $700^{\circ} \mathrm{C}-20 \mathrm{~h}$ & 310 \\
\hline
\end{tabular}

\section{Experimental Procedure}

The Alloy 625 specimens examined in this work were obtained in the form of thin slices from tubes which had seen service for periods from ranging from $28,000 \mathrm{~h}$ to $70000 \mathrm{~h}$ at temperatures close to but not exceeding $600^{\circ} \mathrm{C}$. Prior to being put into service the alloy was heat treated at $1000^{\circ} \mathrm{C}$ for $1 \mathrm{~h}$ and subsequently air cooled. The chemical composition of the alloy is shown in Table I. Post service heat treatments of the alloy are given in table II.

The slices were ground to about $0.10-0.15 \mathrm{~mm}$ thickness for making specimens for TEM examination. Discs of $3 \mathrm{~mm}$ diameter were punched from these foils and electron transparent samples were prepared from the discs by the dual jet electropolishing technique, using an electrolyte containing one part of perchloric acid and four parts of ethanol. Electropolishing was carried out at about 20 volts and the electrolyte temperature was maintained in the range of -25 to $-30^{\circ} \mathrm{C}$. The thin foils so prepared were examined in a JEOL JEM 2000FX TEM with an energy dispersive spectrometer (EDS) attachment.

Electron diffraction analysis, in conjunction with dark field imaging, was used for the identification of the different phases present in the specimens. The compositions of some of these phases were found by EDS, the data obtained being analysed in accordance with the standard Cliff - Lorimer approach [13]. The relative elemental concentrations were determined by using the $\mathrm{K}_{\mathrm{XN}_{\mathrm{N}}}$ values obtained experimentally from binary nickel alloys of known compositions.

\section{Results}

\section{$\underline{\text { Hardness }}$}

The hardness values of solution annealed, long term $(\sim 70000 \mathrm{~h})$ serviced and post-service aged samples are given in table II. It is clear from the table that post service heat treatment has resulted in a softening of alloy but not to the level of the as received material in the solution annealed condition. These results are explained in the discussion section on the basis of microstructural observations.

\section{$\underline{\text { Pre-service Microstructure }}$}

The typical microstructure of the alloy, after being subjected to a heat treatment at $1000^{\circ} \mathrm{C}$ for $1 \mathrm{~h}$ and prior to being put into service, is illustrated in Fig. 1. Except for some randomly distributed blocky precipitates (which were identified by selected area diffraction (SAD) to be of $\mathrm{MC}$ and $\mathrm{M}_{6} \mathrm{C}$ type carbide phases) the microstructure consisted only of austenite grains. The carbide particles 


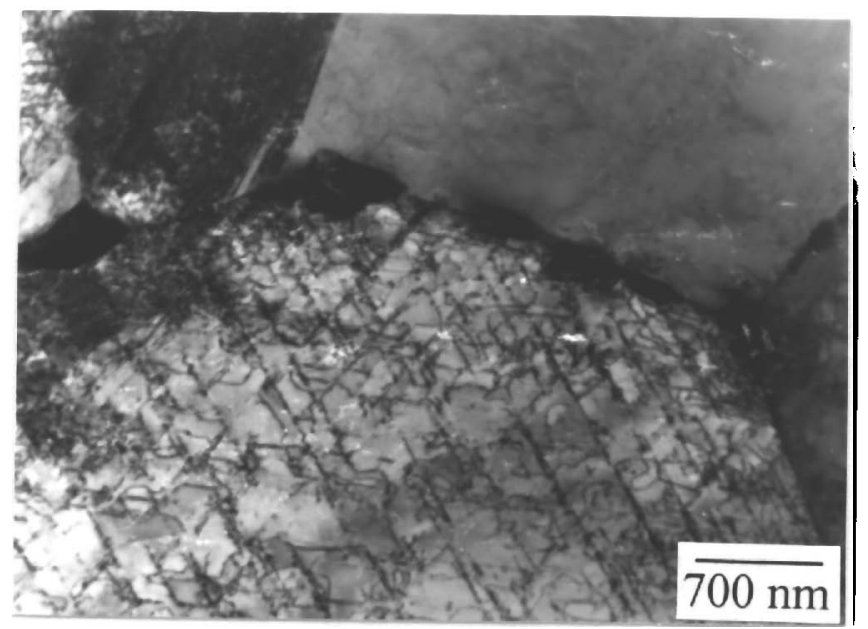

Figure 1: Typical microstructure of solution annealed Alloy 625.

were not found to obey any specific orientation relationship with the austenite matrix. A high density of dislocations, distributed uniformly within the matrix, was another noticeable feature of the microstructure.

\section{$\underline{\text { Post-service Microstructure }}$}

The typical microstructure of the alloy after about $70000 \mathrm{~h}$ of service at temperatures less than but close to $600^{\circ} \mathrm{C}$ is shown in Fig. 2. It could be seen that extensive precipitation had occurred in the alloy, within the austenite grains as well at the grain boundaries, during service. SAD patterns obtained from the austenite grains showed the presence of extra reflections in addition to the austenite reflections. A typical [001] zone axis SAD pattern is shown in Fig. 2a and the corresponding bright field (BF) image in Fig. $2 b$. Similar SAD patterns and microstructures were obtained in obtained in samples which has seen a service life of $28000 \mathrm{~h}$. The superlattice reflections occurring in this SAD pattern in Fig. 2a have been indexed in terms of the $\gamma^{\prime \prime}$ phase and the phase with $\mathrm{Pt}_{2} \mathrm{Mo}$ structure[12]. Dark field(DF) imaging of $\gamma^{\prime \prime}$ particles obtained with a reflection corresponding to one of the $\gamma^{\prime \prime}$ variants is shown in Fig. 2c. These precipitates had a lens shaped morphology and their average size was estimated to be $23 \pm 7 \mathrm{~nm}$.

The superlattice reflections at $1 / 3\{220\}$ positions in the SAD pattern in Fig. 2a could be ascribed to variants of the phase with the $\mathrm{Pt}_{2} \mathrm{Mo}$ type structure. All the six variants of this phase could be identified from superlattice reflections corresponding to them and also by obtaining dark field images of precipitates belonging to these variants. A typical dark field image of one such variant is shown in Fig. 2d. While a majority of these precipitates appeared to have a snowflake like morphology, some of the smaller particles had an ellipsoidal morphology. The precipitate size exhibited quite a large variation, ranging from about $30 \mathrm{~nm}$ to about $300 \mathrm{~nm}$. EDS analysis was carried out on a number of precipitates of this phase with the $\mathrm{Pt}_{2} \mathrm{Mo}$ structure to determine their chemical composition. The X-ray spectra obtained indicated that the precipitates contained only nickel, chromium and molybdenum as the major components. The average precipitate composition, computed from the results of EDS analysis of ten particles, is tabulated in Table III. It could be seen that the nickel content of the $\mathrm{Pt}_{2} \mathrm{Mo}$ type phase was quite close to that of the matrix while its chromium and molybdenum contents were relatively higher, the molybdenum enrichment being quite substantial. The composition of this precipitate phase corresponded to a $\mathrm{Ni}_{2}(\mathrm{Cr}, \mathrm{Mo})$ stoichiometry.

Apart from the superlattice reflections corresponding to the $\gamma^{\prime \prime}$ phase and the orthorhombic phase with the $\mathrm{Pt}_{2} \mathrm{Mo}$ type structure, additional reflections appeared at $1 / 3\{200\}$ positions as well in 

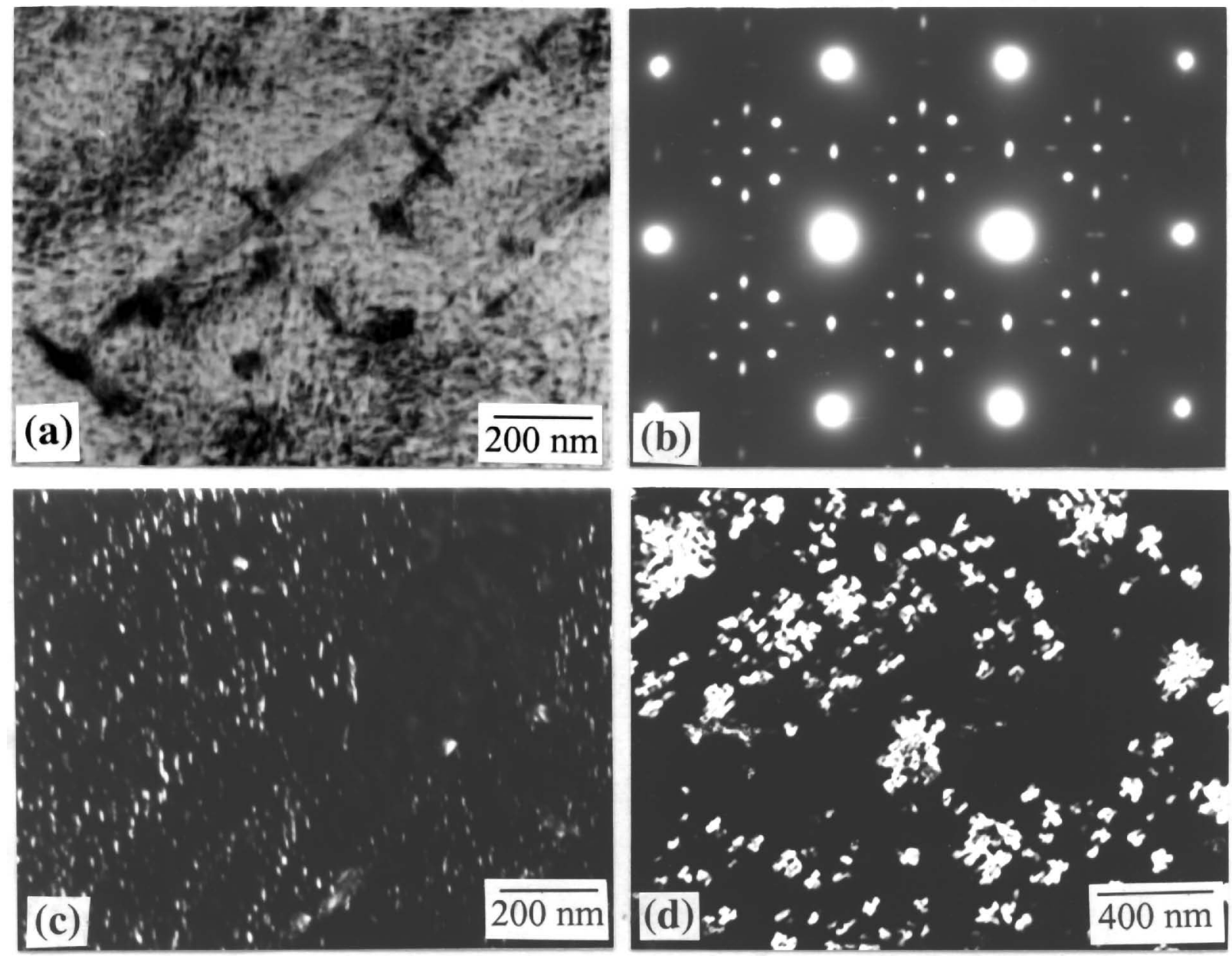

Figure 2: Typical microstructure of Alloy 625 after prolonged ( $70000 \mathrm{~h}$ ) exposure at temperatures close to but less than $600^{\circ} \mathrm{C}$ (referred to as Service alloy). (a) [001] zone axis SAD pattern; (b) BF micrograph revealing extensive precipitation within the grain; (c) DF micrograph with $\{100\}$ type superlattice reflection revealing one variant of $\gamma$ " precipitates; (d) DF imaging with $1 / 3\{220\}$ type reflection revealing an $\mathrm{Ni}_{2}(\mathrm{Cr}, \mathrm{Mo})$ variant.
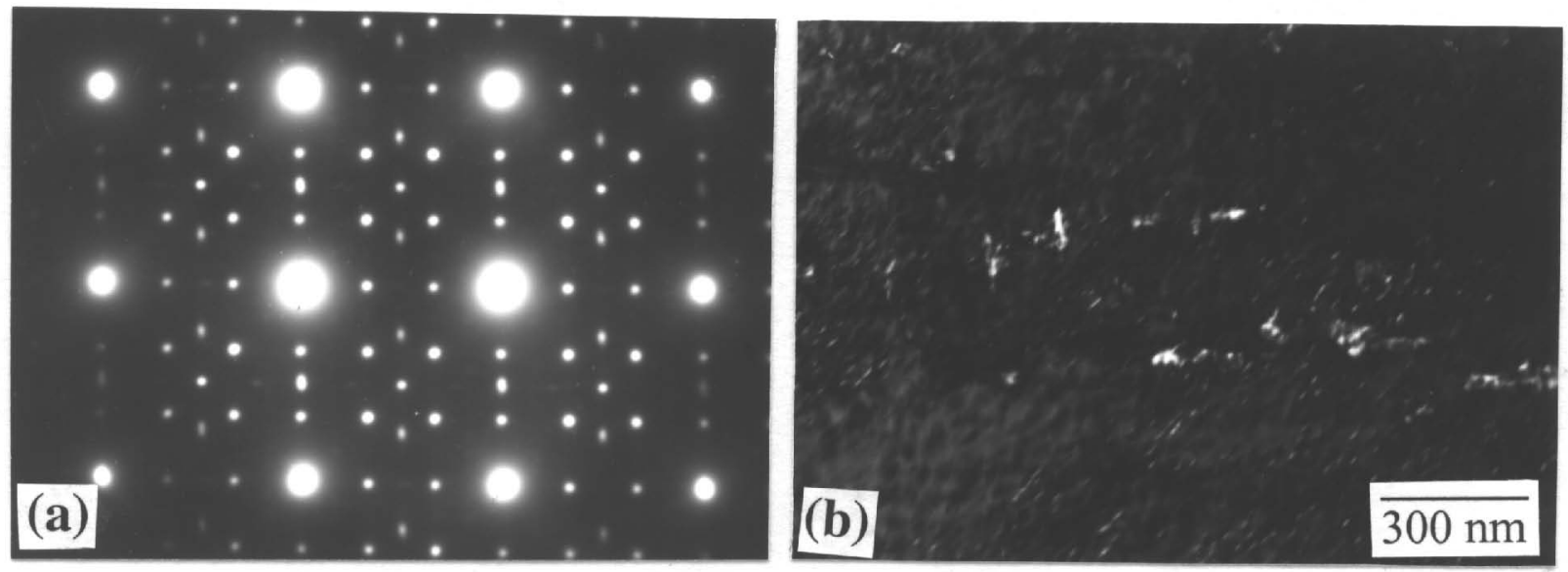

Figure 3: (a) [001] zone axis SAD pattern from areas within the austenite grain of Service alloy showing additional reflections at $1 / 3\{200\}$ positions; (b) DF image from corresponding region with $1 / 3(200)$ reflection revealing carbide precipitates in the matrix. 
$<001>$ zone axis SAD patterns obtained from some regions of the matrix (Fig. 3a). Carbide phases of $\mathrm{M}_{6} \mathrm{C}$ and $\mathrm{M}_{23} \mathrm{C}_{6}$ types could give rise to these reflections. A typical DF image taken with the $1 / 3(200)$ reflection is shown in Fig. 3b. The number density of these carbide particles was not large and they were generally much smaller in size as compared to the precipitates of the orthorhombic phase. EDS analysis of carbide particles located inside the austenite grains revealed that the metallic species present in these particles comprised only nickel, chromium and molybdenum, the concentrations of the three being nearly equal (Table III). In their studies on the chemical compositions of carbide phases in Ni-Cr-Mo alloys, Raghavan et al. [14] have found that $\mathrm{M}_{6} \mathrm{C}$ type carbides can dissolve significant amounts of nickel and chromium. In view of this observation it appeared that the carbide precipitates occurring within the austenite grains were of $\mathrm{M}_{6} \mathrm{C}$ type. It may

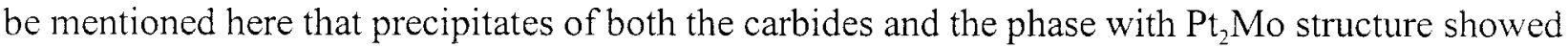
up in DF imaging with 1/3 220$\}$ reflections because of the overlapping of superlattice reflections from the two phases at the $1 / 3\{220\}$ positions. The carbide particles obey a cube-to-cube orientation relationship with the austenite matrix $[5,14]$.

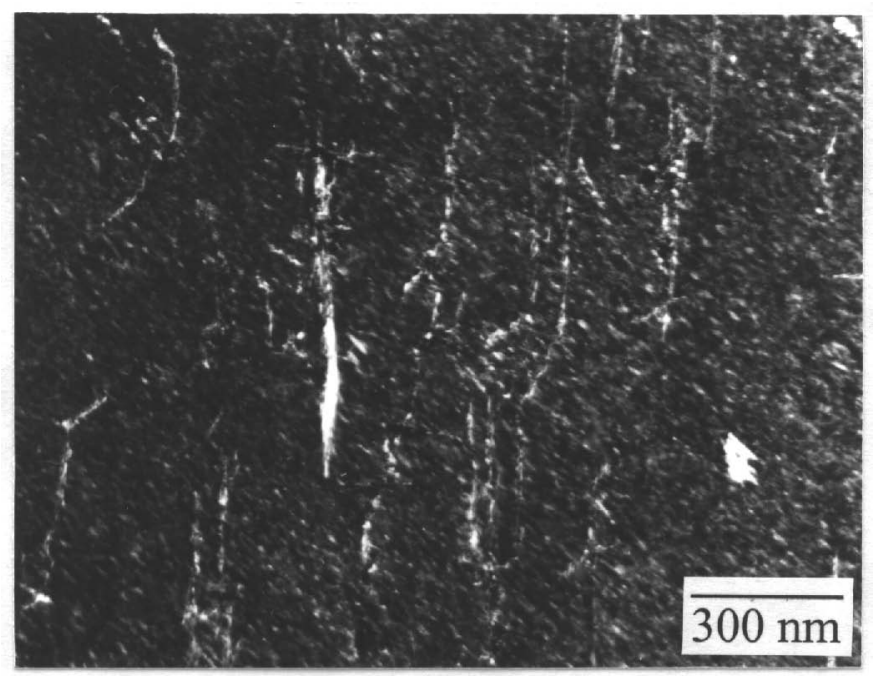

Figure 4: Dislocations in the Service alloy imaged using the weak beam technique.
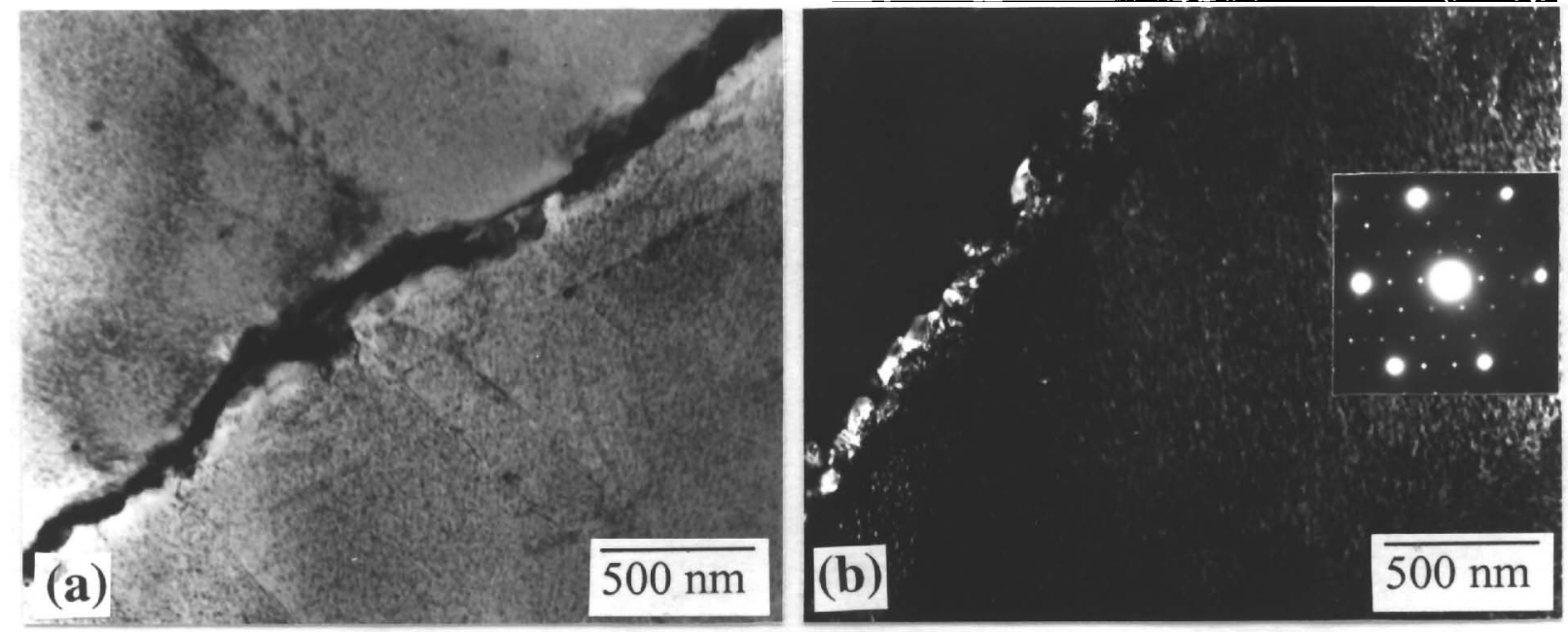

Figure 5: A near continuous layer of carbide precipitates at an austenite grain boundary in the Service alloy. (a) BF micrograph; (b) DFmicrograph. $<110>$ zone axis SAD pattern in the inset in (b) reveals reflections typical of $\mathrm{M}_{23} \mathrm{C}_{6}$ and $\mathrm{M}_{6} \mathrm{C}$ carbides. 
In addition to the intermetallic and the carbide precipitates, a uniform distribution of dislocations was observed in the matrix (Fig. 4). Imaging of these dislocations using the weak beam technique revealed that some of them appeared to have dissociated into partials. The visibility of dislocations along their complete length suggested that the carbide particles within the austenite grains had not precipitated heterogeneously on dislocations.

A near continuous film made up of discrete carbide particles was found to have formed at the austenite grain boundaries. A typical micrograph corresponding to a sample which had seen 50000 $h$ of service is shown in Fig. 5. SAD patterns obtained from the grain boundary carbide precipitates indicated the presence of $\mathrm{M}_{23} \mathrm{C}_{6}$ as well as of $\mathrm{M}_{6} \mathrm{C}$ phases. These particles exhibited a cube-to-cube orientation relationship with the adjacent matrix. In order to identify the nature of carbide particles at the grain boundaries, EDS analysis was performed on a large number of such particles. These particles were identified to be of $\mathrm{M}_{6} \mathrm{C}$ or $\mathrm{M}_{23} \mathrm{C}_{6}$ phases by following the procedure described by Raghavan et al.[14]. On the basis of this analysis, about $75 \%$ of the grain boundary carbides was found to be of the $\mathrm{M}_{23} \mathrm{C}_{6}$ type. The average composition of the carbides obtained is listed in Table III. $\gamma^{\prime \prime}$ precipitate free zones (PFZ) were noticed around a few grain boundaries. The composition profile across the boundary was obtained in order to find out the possible explanation for the occurrence of these $\gamma^{\prime \prime}$ denuded zones. A representative example is given in Fig. 6. A slight molybdenum and chromium depletion could be observed near the PFZ and a small reduction in nickel concentration from the average value could be noticed only on the carbide precipitates. The concentration of other elements upto the grain boundary carbides was very close to the average matrix composition and hence is not plotted in the figure.

\section{Effect of Heat Treatment on Post-Service Microstructure}

In order to examine the effect of short duration heat treatments at temperatures significantly higher than the service temperature on the post-service microstructure, some samples from the post-service material were aged in the temperature range of $600^{\circ} \mathrm{C}-700^{\circ} \mathrm{C}$ for different periods of time. The details of the heat treatments are given in Table III. SAD patterns obtained from most of the regions of these samples contained superlattice reflections corresponding only to the $\gamma^{\prime \prime}$ phase(Fig. 7a). Spots at $1 / 3\{220\}$ positions could be observed in [001] zone axis SAD patterns from a few regions. However, in all these patterns superlattice spots were invariably found to occur at $1 / 3\{200\}$ positions also. These patterns could arise from $\mathrm{M}_{6} \mathrm{C}$ or $\mathrm{M}_{23} \mathrm{C}_{6}$ type carbide phases. These observations suggested that the post-service heat treatments led to the dissolution of the precipitates of the $\mathrm{Ni}_{2}(\mathrm{Cr}, \mathrm{Mo})$ phase. DF imaging with $\{100\}$ reflections showed a uniform distribution of $\gamma^{\prime \prime}$ precipitates (Fig. 7b). The number density of these particles did not appear to have been affected significantly by the heat treatments. The average precipitate size was estimated to be $22 \pm 6 \mathrm{~nm}$, which was approximately the same as that measured in the post-service microstructure. No change in size, morphology or density of carbides precipitated at the grain boundaries was observed after the post- service heat treatments.

\section{Discussion}

\section{Precipitation of $\gamma^{\prime \prime}$ Phase}

Precipitation of $\gamma^{\prime \prime}$ the phase in Alloy 625 on ageing at temperatures in the range of $600^{\circ} \mathrm{C}-750^{\circ} \mathrm{C}$ and the concomitant age hardening effect are well studied [1, 3-8]. However, controlled laboratory experiments aimed at examining $\gamma^{\prime \prime}$ phase precipitation in this alloy at ageing temperatures lower than $600^{\circ} \mathrm{C}$ does not appear to have been carried out. Bajaj et al. [11] have observed that during irradiation by neutrons at $360^{\circ} \mathrm{C}$ in the reactor, the $\gamma^{\prime \prime}$ particle size reduces to half its original value indicating that some dissolution occurrs during irradiation. Thomas and Tait [10] have observed the presence of $\gamma^{\prime \prime}$ precipitates in Alloy 625 samples obtained from a feed stock superheater which had been in service for approximately $50000 \mathrm{~h}$ at temperatures close to $500^{\circ} \mathrm{C}$. They have reported that 
Table III. Chemical composition of different phases in Alloy 625 matrix estimated by EDS

\begin{tabular}{|l|c|c|c|c|}
\hline \multirow{2}{*}{\multicolumn{1}{c|}{ Phase }} & \multicolumn{3}{c|}{ Concentration in wt.\% } \\
\cline { 2 - 5 } & $\mathrm{Ni}$ & $\mathrm{Cr}$ & $\mathrm{Mo}$ & $\mathrm{Nb}$ \\
\hline $\begin{array}{l}\text { Phase with } \mathrm{Pt}_{2} \text { Mo type } \\
\text { structure }\end{array}$ & 61.74 & 25.98 & 12.28 & @ \\
\hline $\begin{array}{l}\text { Secondary carbide in the } \\
\text { matrix }\left(\mathrm{M}_{6} \mathrm{C}\right)\end{array}$ & 39.29 & 32.81 & 27.90 & 13.79 \\
\hline $\begin{array}{l}\mathrm{M}_{23} \mathrm{C}_{6} \text { carbide at the } \\
\text { grain boundary }\end{array}$ & 10.11 & 74.78 & 26.76 & 6.90 \\
\hline $\begin{array}{l}\mathrm{M}_{6} \mathrm{C} \text { carbide at the grain } \\
\text { boundary }\end{array}$ & 37.08 & 30.23 & \\
\hline
\end{tabular}

Values within the bracket denote standard deviation

@ denotes negligible value
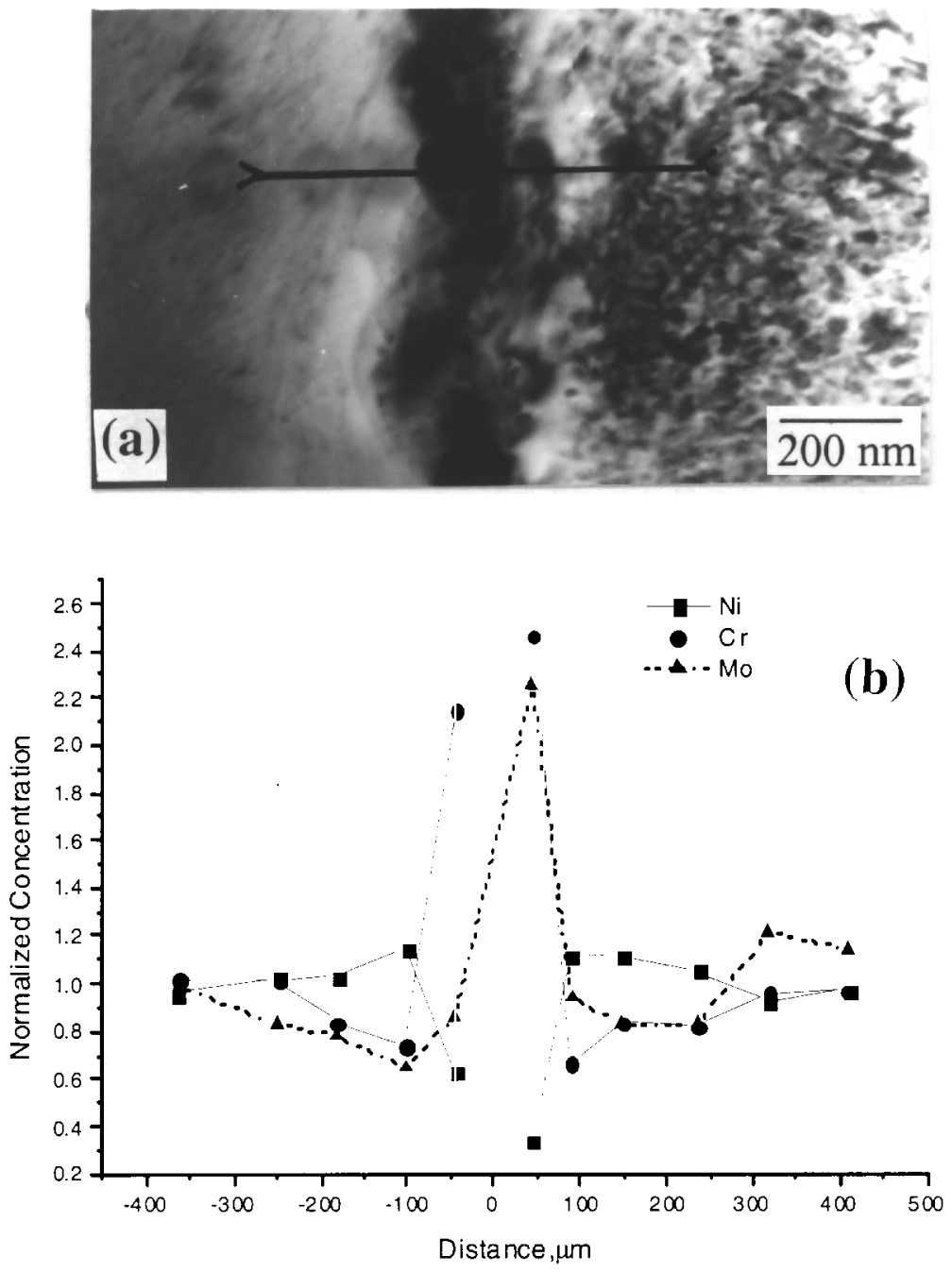

Figure 6: (a) BF micrograph showing $\gamma$ " precipitate free zones near a grain boundary in the Service alloy. (b) The composition profile across the boundary from a region marked in (a). The concentration of elements are normalised with respect to their average matrix composition. The width of the rectangular box represents the thickness of the carbide layer at the grain boundary. 

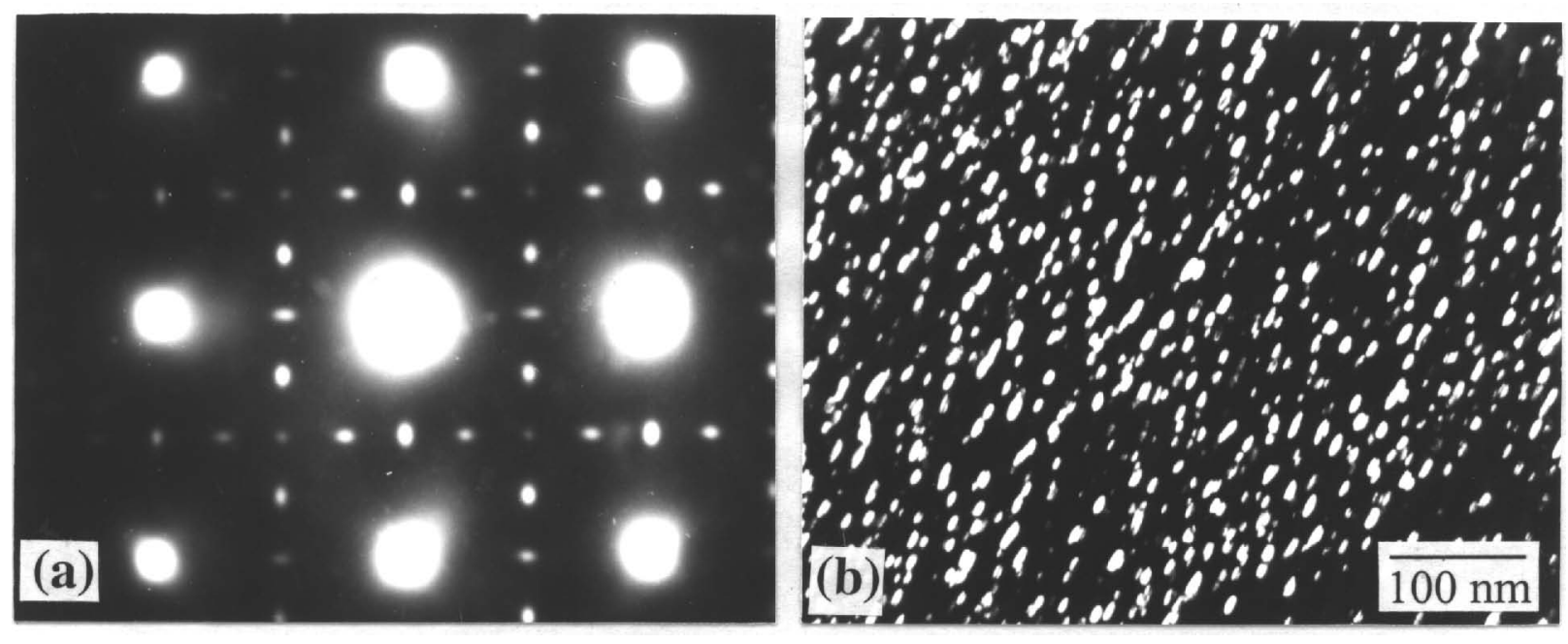

Figure 7: Typical microstructure of the Service alloy specimen subjected to post service heat treatment at $650^{\circ} \mathrm{C}$ for $24 \mathrm{~h}$. (a) [001] zone axis SAD pattern showing reflections corresponding to only $\gamma^{\prime \prime}$ phase. (b) DF micrograph revealing $\gamma$ " precipitate distribution in the matrix

the number density of the precipitates decreases significantly on subjecting this material to a heat treatment at $700^{\circ} \mathrm{C}$ for $12 \mathrm{~h}$. As mentioned earlier, profuse precipitation of the $\gamma^{\prime \prime}$ phase had occurred in the alloy after $28000 \mathrm{~h}$ of service at temperatures close to but lower than $600^{\circ} \mathrm{C}$. Postservice heat treatment did not bring about any significant change, either in the number density or in the average size of the $\gamma^{\prime \prime}$ precipitates. It could be inferred, therefore, that the contributions made by the $\gamma^{\prime \prime}$ precipitates to the strength of the alloy before and after this heat treatment were not much different. Keeping in view the TEM results presented by Thomas and Tait [10], it appears that the enhanced strength and the reduced toughness exhibited by the alloy after prolonged service at intermediate temperatures $\left(-500^{\circ} \mathrm{C}\right)$ can largely be attributed to the precipitation of the $\mathrm{Ni}_{2}(\mathrm{Cr}, \mathrm{Mo})$ phase.

\section{Precipitation of $\mathrm{Ni}_{2}(\mathrm{Cr}, \mathrm{Mo})$ phase}

The TEM investigations study carried out by present authors[12] and Bajaj et al [11] have clearly demonstrated that precipitates of a phase with a $\mathrm{Pt}_{2} \mathrm{Mo}$ type structure formed in Alloy 625 on very long exposure to temperatures up to about $600^{\circ} \mathrm{C}$. The occurrence of such a phase on prolonged ageing at temperatures below $600^{\circ} \mathrm{C}$ has been observed in quite a few chromium-and molybdenumbearing nickel-base alloys such as Hastelloy C, Hastelloy C 276, Hastelloy C4 [15] and Hastelloy $\mathrm{S}$ [16] which contain about $60 \mathrm{wt} \%$ nickel and $14-16 \mathrm{wt} \%$ each of molybdenum and chromium. Alloy 625 contains about $62 \mathrm{wt} \%$ nickel, $21 \mathrm{wt} \%$ chromium and $9 \mathrm{wt} \%$ molybdenum and thus its base composition is very close to those of some of the Hastelloys. It was not surprising, therefore, that a $\mathrm{Pt}_{2} \mathrm{Mo}$ type phase which was shown to correspond to a $\mathrm{Ni}_{2}(\mathrm{Cr}, \mathrm{Mo})$ stoichiometry, formed in Alloy 625 on extended intermediate temperature service.

In the binary nickel-chromium system, the $\mathrm{Ni}_{2} \mathrm{Cr}$ phase, which has a $\mathrm{Pt}_{2} \mathrm{Mo}$ type structure, is known to form in the composition range of $25-36$ at. $\%$ chromium as an equilibrium phase; the orderdisorder transition temperature of this ordered phase is $590^{\circ} \mathrm{C} \mathrm{[17].} \mathrm{In} \mathrm{the} \mathrm{binary} \mathrm{nickel-}$ molybdenum system an ordered phase with $\mathrm{Ni}_{2} \mathrm{Mo}$ stoichiometry and $\mathrm{Pt}_{2} \mathrm{Mo}$ type structure has been reported to form as a metastable phase [18]. Ternary chromium additions to nickel-molybdenum alloys tend to stabilise this phase. In Haynes Alloy 242, containing $25 \mathrm{wt} \%$ molybdenum and $8 \mathrm{wt} \%$ chromium, a $\mathrm{Ni}_{2}(\mathrm{Cr}, \mathrm{Mo})$ phase $\left(\mathrm{Pt}_{2} \mathrm{Mo}\right.$ type structure $)$ has been found to precipitate on ageing at temperatures up to $750^{\circ} \mathrm{C}$ [19]. In view of the similarity in the base compositions of Alloy 625 and 
of some of the Hastelloys, it would not be unreasonable to assume that the $\mathrm{Ni}_{2}(\mathrm{Cr}, \mathrm{Mo})$ phase would not be stable in Alloy 625 at temperatures much in excess of $600^{\circ} \mathrm{C}$. It was indeed observed in the present work that heat treatment at temperatures above $600^{\circ} \mathrm{C}$ led to a complete dissolution of the pre-existing precipitates of this phase which had formed during extended service at temperatures below $600^{\circ} \mathrm{C}$.

The $\mathrm{Ni}_{2}(\mathrm{Cr}, \mathrm{Mo})$ precipitates which form in Hastelloys [15,16] and in Haynes Alloy 242 [19] have been reported to have an ellipsoidal morphology with $\{110\}$ type habit planes. As a consequence of this, the superlattice spots corresponding to this phase show streaking along $\langle 110\rangle$ directions in $\mathrm{SAD}$ patterns. No such streaking of $\mathrm{Ni}_{2}(\mathrm{Cr}, \mathrm{Mo})$ superlattice spots was observed in the present work, indicating that the precipitates of this phase which formed in Alloy 625 did not grow preferentially along any specific direction. They exhibited a snowflake like morphology rather than an ellipsoidal morphology. Investigations on Hastelloys $[15,16]$ have shown that a conspicuous increase in yield strength occurs consequent to ageing treatments at temperatures up to $600^{\circ} \mathrm{C}$ which produce a uniform distribution of fine particles of the $\mathrm{Ni}_{2}(\mathrm{Cr}, \mathrm{Mo})$ phase. That precipitation of this phase occurs in Alloy 625 also on prolonged exposure to temperatures below $600^{\circ} \mathrm{C}$ was clearly demonstrated in the present work.

\section{Precipitation of carbides}

The results of this investigation clearly showed that profuse carbide precipitation occurs at grain boundaries in Alloy 625 during prolonged service. EDS analysis of the carbide particles indicated that the dominant grain boundary carbide forming is the chromium rich $\mathrm{M}_{23} \mathrm{C}_{6}$. This result is in agreement with the observations reported in the literature[5,11]. Carbide precipitation at grain boundaries resulted in the formation of $\gamma^{\prime \prime}$ precipitate free zones (PFZ) at some boundaries. Composition profiles obtained across such boundaries presented in the present investigation indicated that apart from molybdenum and chromium, none of the other pertinent elements showed any appreciable reduction in concentration from the average composition at the precipitate free zones. Raghavan et al. [14] have demonstrated by EDS analysis that the formation of $\mathrm{M}_{23} \mathrm{C}_{6}$ precipitates is associated with chromium and molybdenum depletion in the matrix while the precipitation of $\mathrm{M}_{6} \mathrm{C}$ carbides causes molybdenum depletion near them. Unlike in the case of Alloy $718[20]$, no reasonable explanation could be provided for the formation of PFZ in the present case. The zones denuded of $\gamma^{\prime \prime}$ precipitates near the grain boundaries could generally occur due to solute or vacancy depletion. Since the misfit between the matrix and the $\mathrm{M}_{23} \mathrm{C}_{6}$ and $\mathrm{M}_{6} \mathrm{C}$ phases was not large, the vacancy depletion mechanism could not have been the one operating. It was possible that depletion of one or more solutes near the carbide particles could lead to an enhancement in the solubility of intermetallic phases in these regions, thereby resulting in the formation of PFZs. More detailed studies are warranted to understand the exact mechanism for the formation of PFZ in this alloy. It has been observed that increased grain boundary precipitation results in a reduction in the ductility of the alloy and the fracture mode changes from transgranular to intergranular[20]. This fact has been correlated with the increased precipitation and formation of near-continuous carbide layers at grain boundaries. When the carbide particles are very closely spaced, forming a nearcontinuous film, the distances separating the microcracks would be very small and they could easily join up to facilitate intergranular fracture. The results of the present investigation and those reported earlier [10] demonstrated that the hardness of the alloy decreased after post-service heat treatments. Thomas and Tait [10] have observed that the toughness of the alloy has improved after post-service heat treatment. On the basis of all these facts, one could reasonably conclude that though carbide precipitation at grain boundaries brings about some reduction in ductility of the alloy, the loss of toughness is mainly associated with the combined precipitation of the $\gamma^{\prime \prime}$ and $\mathrm{Ni}_{2}(\mathrm{Cr}, \mathrm{Mo})$ phases. On the basis of post-service heat treatment experiments, Thomas and Tait[10] have chosen a suitable on-line heat treatment to dissolve the $\mathrm{Ni}_{2}(\mathrm{Cr}, \mathrm{Mo})$ phase and this treatment leads to a considerable improvement in the life of the superheaters. 


\section{Conclusions}

On the basis of the present investigation on the microstructure produced in Alloy 625 after prolonged service at temperatures close to but below $600^{\circ} \mathrm{C}$ as well as after post-service heat treatments, the following conclusions could be drawn:

1. Uniform intragranular precipitation of two intermetallic phases - the $\gamma^{\prime \prime}$ phase and a $\mathrm{Ni}_{2}(\mathrm{Cr}, \mathrm{Mo})$ phase - occurred in the austenite matrix, there being three variants of the former and six variants of the latter precipitate species.

2. The $\gamma^{\prime \prime}$ precipitates had an ellipsoidal morphology while the $\mathrm{Ni}_{2}(\mathrm{Cr}, \mathrm{Mo})$ precipitates exhibited a predominantly snowflake like morphology, the average size of both being quite small.

3. The $\mathrm{Ni}_{2}(\mathrm{Cr}, \mathrm{Mo})$ precipitates disappeared almost completely on subjecting the alloy to heat treatments above $600^{\circ} \mathrm{C}$ for short durations, with a concomitant reduction in the hardness of the alloy. This suggests that the $\mathrm{Ni}_{2}(\mathrm{Cr}, \mathrm{Mo})$ phase is not stable at temperatures somewhat in excess of $600^{\circ} \mathrm{C}$ in Alloy 625 and that its precipitation hardens this alloy.

4. A near continuous layer of carbide particles, predominantly of the $\mathrm{M}_{23} \mathrm{C}_{6}$ type formed at the austenite grain boundaries. Carbide precipitates occurring at intragranular locations were mainly of the $\mathrm{M}_{6} \mathrm{C}$ type.

5. A slight reduction of chromium and molybdenum at PFZs near grain boundaries could be observed. More focussed studies is necessary to understand the formation of PFZs in this alloy.

\section{Acknowledgements}

The authors would also like to acknowledge the co-operation and the help received from Mrs, $\mathrm{P}$. Agashe and Mr. P. J. Potdar during the course of this work.

\section{References}

1. H.L. Eiselstein and D.J. Tillack, "Superalloy 718,625 and Various Derivatives", ed. E.A. Loria, TMS, Warrendale, P.A., USA, (1991), 1-14.

2. E.E. Brown and D.R. Muzyka, "The Superalloys II", Ed. C.T. Sims and W.C. Hagel, John Wiley, New York, NY (1987), 165-188.

3. H. Bohm, K. Ehrlich and K.H. Kramer, "Das Ausscheidungsverhalten der Nickellegierung Inconel 625", Metall, 24 (1970), 139-144.

4. F. Garzarotli, A. Gerscha and K.P. Francke, "Untersuchungen über das Ausscheidungsverhaiten und die mechanischen Eigenschaften der Legierung Inconel 625", Z. Metallkunde, 60 (1969), 643652.

5. S. Floreen, G.E. Fuchs and W.J. Yang, "The Metallurgy of Alloy 625", Superalloys 718, 625. 706 and Various Derivatives, TMS, Pittsburgh, PA, USA, (1994), 13-38. 
6. M. Sundararaman, P. Mukhopadhyay and S. Banerjee, "Precipitation of the $\delta-\mathrm{Ni}_{3} \mathrm{Nb}$ Phase in Two Nickel Base Superalloys", Metall. Trans., 19A (1988), 453-465.

7. M. Sundararaman, P. Mukhopadhyay and S. Banerjee, "Heterogeneous precipitation of the $\gamma^{\text {" }}$ Phase in Alloy 625", Materials Science Forum, 3 (1985), 273-280.

8. M. Sundararaman, R. Kishore and P. Mukhopadhyay, "Some Aspects of the Heterogeneous Precipitation of the Metastable $\gamma$ " Phase in Alloy 625", Superalloys 718, 625, 706 and Various Derivatives, ed. E.A. Loria, TMS, Warrendale, PA, USA, (1994), 405-418.

9. J.F. Radavich and A. Fort " "Effects of Long Time Exposure in Alloy 625 at $1200^{\circ} \mathrm{F}, 1400^{\circ} \mathrm{F}$ and $1600^{\circ}$ F", Superalloys 718, 625, 706 and Various Derivatives, Ed. E.A. Loria, TMS, Warrendale, P.A. USA, (1994), 635-647.

10. C. Thomas and P. Tait, "The Performance of Alloy 625 in Long Term Intermediate Temperature Applications", Int. J. Pressure Vessels \& Piping, 59 (1994), 41-49.

11. R. Bajaj, W.J. Mills, M.R. Lebo, B.Z. Hyatt and M.G. Burke, "Irradiation-Assisted Stress Corossion Cracking of HTH Alloy X-750 and Alloy 625", Proceedings of the Seventh International Symposium on Environmental Degradation of Materials in Nuclear Power Systems-Water Reactors, Ed. G. Airey et al., NACE International, Houston, TX, USA, (1995), 1093-1107.

12. M. Sundararaman, Lalit Kumar, G.E. Prasad, P. Mukhopadhyay and S. Banerjee, "Precipitation of an Intermetallic Phase with $\mathrm{Pt}_{2}$ Mo Type Structure in Alloy 625", Metall. \& Mater. Trans., 30A (1999), 41-52.

13. G. Cliff and G.W. Lorimer, J. Microscopy, 103 (1975), 203-207.

14. M. Sundararaman, P. Mukhopadhyay and S. Banerjee, "Carbide Precipitation in Nickel Base Superalloys 718 and 625 and their Effect on Mechanical Properties", Superalloys 718, 625, 706, 725 and Various Derivatives, Ed. E.A. Loria, TMS, Warrendale, PA, USA, (1997), 3677-378.

15. H.W. Tawancy, R.B. Herchenrocder and A.J. Asphanani, "High Performance Ni-Cr-Mo-W Alloy", J. Metals, 35(6) (1983), 37-43.

16. H.W. Tawancy, "Order Strengthening in a Nickel base Superalloy (Hastelloy Alloy S)", Metall. Trans., $11 \mathrm{~A}(1980), 1764-65$.

17. P. Nash, "Binary Alloy Phase Diagram", Ed. T.B. Massalski, H. Okamoto, P.R. Subramanian and L. Kacprzak, ASM, Materials Park, Ohio, USA, (1992), 1298-1302.

18. U.D. Kulkarni and S. Banerjee, "Phase Separation during Early Stages of Ordering in $\mathrm{Ni}_{3} \mathrm{Mo}$ ", Acta Metall., 36 (1988), 413-424.

19. M. Kumar and V.K. Vasudevan, "Ordering reactions in a Ni-25Mo-8Cr Alloy", Acta Metall. et Mater., 44 (1996), 1591-1600.

20. M. Raghavan, R.P. Mueller, C.F. Klein and G.A. Vaughn, "Carbides in Ni-Cr-Mo System", Scripta Metall. et Mater., 17 (1983), 1189-1194. 